\title{
NUTRITIONAL CONSIDERATIONS IN FRAIL OLDER PATIENTS WITH COVID-19
}

\author{
D. AZZOLINO ${ }^{1,2}$, E. SAPORITI ${ }^{1}$, M. PROIETTI ${ }^{1,2,3}$, M. CESARI $^{1,2}$ \\ 1. Geriatric Unit, Fondazione IRCCS Ca' Granda Ospedale Maggiore Policlinico, Milan, Italy; 2. Department of Clinical Sciences and Community Health, University of Milan, Milan, \\ Italy; 3. Liverpool Centre for Cardiovascular Science, University of Liverpool, and Liverpool Heart \& Chest Hospital, United Kingdom. Corresponding author: Domenico Azzolino. \\ Geriatric Unit, Fondazione IRCCS Ca' Granda Ospedale Maggiore Policlinico; Via Pace 9, 20122 Milan, Italy. Email: domenico.azzolino@policlinico.mi.it
}

\begin{abstract}
The COVID-19 pandemic is posing an unprecedented challenge to healthcare systems worldwide. Older adults, which frequently present multiple chronic comorbidities, are more susceptible to COVID-19 and experience more likely negative outcomes, in terms of disease severity and mortality. However, chronological age per se may not entirely explain the dramatic scenario described among the frailest and oldest persons. Comorbidities and functional status may indeed play a relevant role. Patients at high risk of adverse clinical outcomes in COVID-19 infection are the same at risk of malnutrition, namely older adults and multimorbid individuals. In fact, COVID-19 can negatively impact on nutritional status, both in patients admitted to the hospital with the most severe manifestations of the infection, as well as in those who experience milder/ asymptomatic forms of the disease. Despite being quite difficult in these emergency circumstances, nutritional status needs to be assessed in all COVID-19 patients upon admission and during hospital stay. Early nutritional support should be guaranteed in order to improve several malnutrition-related adverse outcomes. The evaluation of the nutritional status is today even more crucial than in normal times given the delicate status of older patients with COVID-19.
\end{abstract}

Key words: Aging, sarcopenia, malnutrition, SARS - CoV-2, nutrition, inflammation.

The COVID-19 pandemic is posing an unprecedented challenge to healthcare systems worldwide. From the beginning of December 2019 in Wuhan (China), the pandemic is spreading globally, especially in Italy, Spain and United States. Older adults, which frequently present multiple chronic comorbidities, are more susceptible to COVID-19 and experience more likely negative outcomes, in terms of disease severity and mortality (1-3). However, chronological age per se may not entirely explain the dramatic scenario described among the frailest and oldest persons. Comorbidities and functional status may indeed play a relevant role. The clinical symptoms of COVID-19 include fever, dyspnea, dry cough and fatigue. Additionally, diarrhea may be present in some patients and severe cases may develop into acute respiratory distress syndrome (ARDS) and septic shock (4). Patients with the most severe forms of COVID-19 may require mechanical ventilation and intensive care unit (ICU) support. Actually, infections in older adults may often have atypical presentations (5). Fever response could be blunted (especially in the frailest), cough and dyspnea may present as a decline in function (such as impaired mobility or falls), cognitive impairment may appear together with the exacerbation of pre-existent heart failure or a previously known respiratory condition (6). COVID19 can lead to a rapid activation of the innate immune cells, particularly in those patients developing the most severe forms of the disease. Infected patients may exhibit elevated levels of pro-inflammatory cytokines (e.g., TNF, IL-1 $\beta$, IL-6, IL-8, G-CSF and GM-CSF), as well as chemokines (e.g., MCP1, IP10 and MIP1 $\alpha$ ) (7). In particular, lymphocytopenia, high levels of C-reactive protein and D-dimer seem quite common (8).
Malnutrition is highly prevalent in older people, and represents a major burden responsible for severe health-related negative outcomes $(9,10)$. Patients at high risk of adverse clinical outcomes in COVID-19 infection are the same at risk of malnutrition, namely older adults and multimorbid individuals (11). Unfortunately, nutritional status is already poorly considered in the routinely clinical practice of normal times. Indeed, attention to this critical aspect for the health of the aging individual seems dramatically ignored in the acute care units that are today overwhelmed by the COVID-19 emergency, despite the evidence showing how malnutrition negatively impacts on the patients' prognosis and recovery. Alongside, sarcopenia is one of the most prominent conditions in older people. It is defined as the loss of muscle mass and strength leading to poor function (12). Sarcopenia is closely related to malnutrition, and has been indicated as one of its clinical manifestations (13). Interestingly, sarcopenia has recently been proposed as a whole-body process not merely limited to lower limbs, but also affecting muscles dedicated to breathing and swallowing (14). In other words, sarcopenia may concur at adversely affecting respiratory function, which is already acutely compromised in COVID-19 patients. It is thus evident why malnutrition and sarcopenia can easily predispose to the onset of poor clinical outcomes in COVID-19.

COVID-19 can negatively impact on nutritional status, both in patients admitted to the hospital with the most severe manifestations of the infection, as well as in those who experience milder/asymptomatic forms of the disease. In fact, the need for social distancing and self-isolation during the COVID-19 pandemic can easily change their preventive meaning into serious consequences for frail older people (15, 


\section{THE JOURNAL OF NUTRITION, HEALTH \& AGING}

16), especially challenging their nutritional status. Depression and loneliness as well as reduced food availability may be determined by those necessary public health countermeasures, unavoidably leading to changes in food quality and quantity in the older person's diet (17). In this context, telemedicine may be helpful both to support ICUs patients (18) and for remote monitoring of isolated patients $(15,19)$. On the other hand, obesity has been indicated as a risk factor for severe complications in COVID-19 patients (20). An enhanced inflammatory burden, as well as a compromised respiratory function may already be present in obese individuals, who may present more difficulties in the dynamics of ventilation (21). It is noteworthy that body composition tends to change with aging, driving the ratio between lean and fat mass in favor of the latter. In other words, older persons with sarcopenia may easily present the detrimental condition of sarcopenic obesity that may represent a step forward in the vicious cycle of respiratory dysfunction triggered by the SARS-CoV-2 infection (22).

Screening for malnutrition should be normally conducted as a part of the routine clinical care, especially at the hospital admission and at every major change of the individual's health status. In fact, at least one-third of the newly admitted patients present some degree of malnutrition (23). Additionally, it has been documented that among those who are not malnourished at the time of the admission, nearly one third may develop malnutrition during the hospital stay (24), partly due to the many conditions (e.g., comorbidities, inflammatory diseases, infections) enhancing the individual's energy expenditure and catabolism (25). Malnutrition compromises the immune response and further increases the risk of infections, with longer hospital stays and convalescence periods (9, 25-27). As a consequence, recovery from pathological conditions is particularly delayed in malnourished people. The screening of the nutritional status with the traditional tools can be challenging in some situations, especially in critically ill patients. Some tools might be quite difficult to administer, for example in the context of serious cases of COVID-19. In these cases, rapid screening tools to identify patients malnourished or at risk of malnutrition can, however, still be adopted. For example, the Nutrition Risk Screening 2002 (NRS- 2002) (28), the malnutrition universal screening tool (MUST) (29), or the Nutrition Risk in the Critically Ill (NUTRIC) (30) may represent useful and feasible options for including the assessment of nutrition in the most critical situations we are today living. The NRS-2002 includes information about recent dietary intake, weight loss, disease severity, and age. The MUST includes three independent criteria: current weight status using body mass index, unintentional weight loss, and acute disease effect that has induced a phase of nil-per-os for $>5$ days. Although relatively easy to be implemented, it should be considered that their validation in critically ill patients is still missing. On the other hand, the NUTRIC is based on age, disease severity evaluated by the APACHE II and Sequential
Organ Failure Assessment (SOFA) scores, comorbidities, days from hospital to ICU admission and inflammation assessed by IL-6 levels. Since IL-6 levels may not be routinely performed in most settings, a modified form has been validated.

For what concerns nutritional interventions, the amount of energy and proteins should be individually adapted according to the patient's nutritional status, pre-illness physical activity level, clinical conditions and preferences (31). Older adults need more proteins than young and adult individuals, because of a declined anabolic response and an increased catabolism (32). In particular, it is generally recommended a protein intake of at least $1.0 \mathrm{~g} / \mathrm{kg}$ of body weight/day in older people to maintain muscle mass, increasing the intake up to $1.2-1.5 \mathrm{~g} / \mathrm{kg}$ of body weight/day in presence of acute or chronic illnesses. In the presence of highly catabolic conditions (such as the wasting syndrome caused by severe forms of COVID-19), the amount of required proteins might even be increased up to $2.0 \mathrm{~g} / \mathrm{kg}$ of body weight/day $(32,33)$. Energy intake is also pivotal. If caloric provision is not sufficient to meet the demand, body fat and muscles are catabolized to provide energy (34). In this scenario, it is important to remind that older people frequently fail to ingest a significant amount of food or, more specifically, proteins in a single meal. Therefore, a supplementation strategy needs to be frequently considered. Supplementation with essential amino acids may overcome anabolic resistance since they are the primary stimulus for protein synthesis. A high amount of protein per meal (i.e., 25-30 g with at least $2.5 \mathrm{~g}$ of leucine) is required for guaranteeing an adequate anabolic response of the aging skeletal muscle (32). Other strategies may include supplementation with specific multi-nutrient formulas providing both macro- and micronutrients. They should be given to older people with or at risk for malnutrition who fail to ingest adequate amounts of energy and nutrients with foods, with the final aim of reducing the risk of health-related adverse outcomes (9).

In many serious cases, such as COVID-19 patients requiring mechanical ventilation in ICUs, it is not possible to ensure energy and nutrient intake per os. Therefore, enteral nutrition (EN) becomes essential in those patients. It has been shown that early EN decreases the risk of complications and improves the prognosis at discharge (35). Particular attention should be paid to the so-called refeeding syndrome (RFS), which is an often neglected condition not confined solely to EN or parenteral nutrition $(\mathrm{PN})$. In fact, malnourished older patients seem to have a higher risk of RFS (9). In this population, the target of energy intake should be slowly and carefully achieved (11). Therefore, it is recommended a close monitoring of serum levels of phosphate, magnesium, potassium and thiamine during the first three days after EN or PN (31). Last but not least, malnutrition exacerbates the condition of pressure ulcers, which are common in older hospitalized patients, especially in those admitted to ICUs, mainly for the forced immobilization. Patients with pressure ulcers may need more proteins (i.e., $1.5-2.0 \mathrm{~g} / \mathrm{kg}$ of body weight/day) because of wound fluid 


\section{NUTRITIONAL CONSIDERATIONS IN FRAIL OLDER PATIENTS WITH COVID-19}

loss (36). In fact, pressure ulcers can induce a catabolic state, hypermetabolism, protein-calorie malnutrition and dehydration as a consequence of a prolonged inflammatory state (37).

In conclusion, despite being quite difficult in these emergency circumstances, nutritional status needs to be assessed in all COVID-19 patients upon admission and during hospital stay. Early nutritional support should be guaranteed in order to improve several malnutrition-related adverse outcomes, including morbidity, mortality, immune dysfunction, hospital readmission, length of stay and finally healthcare costs. The evaluation of the nutritional status is today even more crucial than in normal times given the delicate status of older patients with COVID-19.

Disclosures: No conflict of interest to declare.

\section{References}

1. Huang C, Wang Y, Li X, Ren L, Zhao J, Hu Y, et al. Clinical features of patient infected with 2019 novel coronavirus in Wuhan, China. The Lancet. 2020 Feb;395(10223):497-506.

2. AlGhatrif M, Cingolani O, Lakatta EG. The Dilemma of Coronavirus Disease 2019 Aging, and Cardiovascular Disease: Insights From Cardiovascular Aging Science. JAMA Cardiol [Internet]. 2020 Apr 3 [cited 2020 Apr 17]; Available from: https:// jamanetwork.com/journals/jamacardiology/fullarticle/2764300

3. Liu K, Chen Y, Lin R, Han K. Clinical features of COVID-19 in elderly patients: A comparison with young and middle-aged patients. J Infect. 2020 Mar 27;

4. Wan S, Xiang Y, Fang W, Zheng Y, Li B, Hu Y, et al. Clinical features and treatment of COVID-19 patients in northeast Chongqing. Journal of Medical Virology [Internet] [cited 2020 Apr 17];n/a(n/a). Available from: https://onlinelibrary.wiley.com/doi/ abs/10.1002/jmv.25783

5. Norman RE, Stall NM, Sinha SK. Typically Atypical: COVID-19 Presenting as a Fall in an Older Adult. J Am Geriatr Soc. 2020 Apr 28;

6. Nikolich-Zugich J, Knox KS, Rios CT, Natt B, Bhattacharya D, Fain MJ. SARS CoV-2 and COVID-19 in older adults: what we may expect regarding pathogenesis, immune responses, and outcomes. GeroScience. 2020 Apr 10;1-10.

7. Schett G, Sticherling M, Neurath MF. COVID-19: risk for cytokine targeting in chronic inflammatory diseases? Nature Reviews Immunology. 2020 Apr 15;1-2.

8. Cao X. COVID-19: immunopathology and its implications for therapy. Nature Reviews Immunology. 2020 Apr 9;1-2.

9. Volkert D, Beck AM, Cederholm T, Cereda E, Cruz-Jentoft A, Goisser S, et al Management of Malnutrition in Older Patients-Current Approaches, Evidence and Open Questions. Journal of Clinical Medicine. 2019 Jul;8(7):974.

10. Margetts BM, Thompson RL, Elia M, Jackson AA. Prevalence of risk of undernutrition is associated with poor health status in older people in the UK. Eur J Clin Nutr. 2003 Jan;57(1):69-74.

11. Barazzoni R, Bischoff SC, Breda J, Wickramasinghe K, Krznaric Z, Nitzan D, et al. ESPEN expert statements and practical guidance for nutritional management of individuals with SARS-CoV-2 infection. Clin Nutr [Internet]. 2020 Mar 31 [cited 2020 May 1]; Available from: https://www.ncbi.nlm.nih.gov/pmc/articles/PMC7138149/

12. Cruz-Jentoft AJ, Landi F. Sarcopenia. Clin Med. 2014 Jan 4;14(2):183-6.

13. Cederholm T, Jensen GL, Correia MITD, Gonzalez MC, Fukushima R, Higashiguchi T, et al. GLIM criteria for the diagnosis of malnutrition - A consensus report from the global clinical nutrition community. Clin Nutr. 2019;38(1):1-9.

14. Azzolino D, Damanti S, Bertagnoli L, Lucchi T, Cesari M. Sarcopenia and swallowing disorders in older people. Aging Clin Exp Res. 2019 Jun;31(6):799-805.

15. Berg-Weger M, Morley JE. Loneliness and Social Isolation in Older Adults During the Covid-19 Pandemic: Implications for Gerontological Social Work. J Nutr Health Aging [Internet]. 2020 Apr 14 [cited 2020 May 2]; Available from: https://doi. org/10.1007/s12603-020-1366-8

16. Morley JE, Vellas B. COVID-19 and Older Adult. J Nutr Health Aging. 2020 Apr $1 ; 24(4): 364-5$
17. Steinman MA, Perry L, Perissinotto CM. Meeting the Care Needs of Older Adults Isolated at Home During the COVID-19 Pandemic. JAMA Intern Med [Internet]. 2020 Apr 16 [cited 2020 Apr 21]; Available from: https://jamanetwork.com/journals/ jamainternalmedicine/fullarticle/2764748

18. Srinivasan SR. TELE-ICU in the Age of COVID-19: Built for this Challenge. J Nut Health Aging [Internet]. 2020 Apr 25 [cited 2020 May 2]; Available from: https://doi. org/10.1007/s12603-020-1376-6

19. Abbatecola AM, Antonelli-Incalzi R. COVID-19 Spiraling of Frailty in Older Italian Patients. J Nutr Health Aging [Internet]. 2020 Apr 7 [cited 2020 May 2]; Available from: https://doi.org/10.1007/s12603-020-1357-9

20. Laviano A, Koverech A, Zanetti M. Nutrition support in the time of SARS-CoV-2 (COVID-19). Nutrition [Internet]. 2020 Apr 2 [cited 2020 Apr 22]; Available from: https://www.ncbi.nlm.nih.gov/pmc/articles/PMC7132492/

21. Dietz W, Santos-Burgoa C. Obesity and its Implications for COVID-19 Mortality. Obesity [Internet]. [cited $2020 \mathrm{Apr} 22$ ];n/a(n/a). Available from: https://onlinelibrary. wiley.com/doi/abs/10.1002/oby.22818

22. Stenholm S, Harris TB, Rantanen T, Visser M, Kritchevsky SB, Ferrucci L. Sarcopenic obesity: definition, cause and consequences. Curr Opin Clin Nutr Metab Care. 2008 Nov;11(6):693-700.

23. Barker LA, Gout BS, Crowe TC. Hospital malnutrition: prevalence, identification and impact on patients and the healthcare system. Int J Environ Res Public Health 2011;8(2):514-27.

24. Braunschweig C, Gomez S, Sheean PM. Impact of declines in nutritional status on outcomes in adult patients hospitalized for more than 7 days. J Am Diet Assoc. 2000 Nov;100(11):1316-22; quiz 1323-4.

25. Orlandoni P, Venturini C, Jukic Peladic N, Costantini A, Di Rosa M, Cola C, et al Malnutrition upon Hospital Admission in Geriatric Patients: Why Assess It? Fron Nutr [Internet]. 2017 Oct 30 [cited 2020 Apr 15];4. Available from: https://www.ncbi nlm.nih.gov/pmc/articles/PMC5670098/

26. Neloska L, Damevska K, Nikolchev A, Pavleska L, Petreska-Zovic B, Kostov M. The Association between Malnutrition and Pressure Ulcers in Elderly in Long-Term Care Facility. Open Access Maced J Med Sci. 2016 Sep 15;4(3):423-7.

27. Abizanda P, Sinclair A, Barcons N, Lizán L, Rodríguez-Mañas L. Costs of Malnutrition in Institutionalized and Community-Dwelling Older Adults: A Systematic Review. J Am Med Dir Assoc. 2016 Jan;17(1):17-23.

28. Kondrup J, Rasmussen HH, Hamberg O, Stanga Z, Ad Hoc ESPEN Working Group. Nutritional risk screening (NRS 2002): a new method based on an analysis of controlled clinical trials. Clin Nutr. 2003 Jun;22(3):321-36.

29. Stratton RJ, Hackston A, Longmore D, Dixon R, Price S, Stroud M, et al. Malnutrition in hospital outpatients and inpatients: prevalence, concurrent validity and ease of use of the 'malnutrition universal screening tool' ('MUST') for adults. Br J Nutr. 2004 Nov;92(5):799-808.

30. Heyland DK, Dhaliwal R, Jiang X, Day AG. Identifying critically ill patients who benefit the most from nutrition therapy: the development and initial validation of a novel risk assessment tool. Crit Care. 2011;15(6):R268.

31. Volkert D, Beck AM, Cederholm T, Cruz-Jentoft A, Goisser S, Hooper L, et al ESPEN guideline on clinical nutrition and hydration in geriatrics. Clin Nutr. 2019 Feb;38(1):10-47.

32. Bauer J, Biolo G, Cederholm T, Cesari M, Cruz-Jentoft AJ, Morley JE, et al. Evidence-Based Recommendations for Optimal Dietary Protein Intake in Older People: A Position Paper From the PROT-AGE Study Group. Journal of the American Medical Directors Association. 2013 Aug 1;14(8):542-59.

33. Deutz NEP, Bauer JM, Barazzoni R, Biolo G, Boirie Y, Bosy-Westphal A, et al Protein intake and exercise for optimal muscle function with aging: recommendations from the ESPEN Expert Group. Clin Nutr. 2014 Dec;33(6):929-36.

34. Cruz-Jentoft AJ, Kiesswetter E, Drey M, Sieber CC. Nutrition, frailty, and sarcopenia. Aging Clin Exp Res. 2017 Feb;29(1):43-8.

35. Allen K, Hoffman L. Enteral Nutrition in the Mechanically Ventilated Patient. Nutr Clin Pract. 2019 Aug;34(4):540-57.

36. Iizaka S, Sanada H, Nakagami G, Sekine R, Koyanagi H, Konya C, et al. Estimation of protein loss from wound fluid in older patients with severe pressure ulcers. Nutrition. 2010 Sep;26(9):890-5

37. Saghaleini SH, Dehghan K, Shadvar K, Sanaie S, Mahmoodpoor A, Ostadi Z. Pressure Ulcer and Nutrition. Indian J Crit Care Med. 2018 Apr;22(4):283-9. 